\section{Re: Evaluation of an Ongoing Diabetes Group Medical Visit in a Family Medicine Practice}

To the Editor: We want to share our experience with a similar patient demographic using diabetes shared medical appointments (SMAs). The report, by Cunningham et al. ${ }^{1}$, describes a series of four 2-hour sessions. One hour is dedicated to a traditional one-on-one medical appointment with additional time for goal setting, while hour two is group diabetes self-management education. These are two different components, not an SMA.

The traditional one-on-one medical visit does not work for the care of chronic medical conditions, as exemplified by the low number of people with diabetes meeting goals for HbA1c, blood pressure, and lipids. Our group has previously described a multidisciplinary SMA model that incorporates medical care (directed by an endocrinologist), patient support, and interactive group education with improved access to care and lower HbA1c levels. ${ }^{2}$ The value of an SMA lies in patient education, empowerment, and engagement. The tagline for every SMA should be, "What happens in the group is good for everyone in the group." Over time, patients build relationships with staff and other patients that would be challenging to develop in a limited number of sessions.

We appreciate the work our colleagues across the Delaware River have done to improve the care of patients with diabetes. We would encourage them to continue their work while changing the model to promote more sharing of patient experiences.

We call for changes on a national level to develop SMA best practices to aid in further evaluation of this innovative care model, develop a national working group to share SMA models and experiences across disease states, and for medical associations to designate time at national conferences to new models of care delivery.

Valerie S. Ganetsky, PharmD, BCPS, Associate Professor of Clinical Pharmacy, University of the Sciences, Philadelphia College of Pharmacy, Research Fellow, University of Pennsylvania Perelman School of

Medicine; Steven Kaufman, MD, Associate Professor of Medicine, Cooper Medical School of Rowan

University., Medical Director, Urban Health Institute, Division Head, Endocrinology and Metabolism

\section{References}

1. Cunningham, AT, Delgado, DJ, Jackson, JD et al. Evaluation of an Ongoing Diabetes Group Medical Visit in a Family Medicine Practice. J Am Board Fam Med. 2018;31: 279-85.

2. Ganetsky, V, Adams, R, Coolman, T, Brenner, J, Kaufman, S. Specialty diabetes group medical visits improve access to care and clinical outcomes at lower cost in an underserved patient population. Diabetes 2016 Jun;65(Supplement 1): 2308-Pub;582.

doi: $10.3122 /$ jabfm.2018.05.180113

The above letter was referred to the author of the article in question, who offers the following reply.

\section{Response: Re: Evaluation of an Ongoing Diabetes Group Medical Visit in a Family Medicine Practice}

To the Editor: We thank Steven Kaufman, MD; and Valerie S. Ganetsky, PharmD, BCPS and for their response to our article ${ }^{1}$ evaluating a diabetes group medical visit (GMV) and for sharing their experience implementing a diabetes shared medical appointment (SMA). We applaud their implementation of an ongoing diabetes SMA.

As the authors illustrate, the terminology for these types of group visits (GMV vs SMA) varies. However, the terms are ultimately interchangeable; both refer to group visits that incorporate medical care and group self-management education. ${ }^{2,3}$ While our program has a different structure than that of Drs. Kaufman and Ganetsky, we do want to clarify that our participants have opportunities to interact and support 1 another during the diabetes selfmanagement education component of our GMV. In fact, an earlier study of our diabetes GMV, consisting of interviews with former participants, showed that a substantial proportion of participants found that the program offered peer support and important opportunities to learn about diabetes self-management from their peers. $^{4}$

In addition, we agree with the authors' call for national best practices for group visits, a national working group, and national conferences focused on group visits and other care delivery innovations. While diabetes group visits hold promise as a patient-centered approach to chronic disease management, more research is needed to identify the optimal group visit size, frequency, structure, and payment mechanisms ${ }^{5}$ that will make these visits effective and sustainable in primary care practices.

Amy T. Cunningham, PhD, MPH

Department of Family and Community Medicine, Thomas Jefferson University, Philadelphia, PA

To see this article online, please go to: http://jabfm.org/content/ 31/5/828.full.

\section{References}

1. Cunningham AT, Delgado DJ, Jackson JD, et al. Evaluation of an ongoing diabetes group medical visit in a family medicine practice. The Journal of the American Board of Family Medicine. 2018;31:279-81. 
2. Ridge T. Shared medical appointments in diabetes care: A literature review. Diabetes Spectrum 2012;25:72-5.

3. American Academy of Family Physicians. Shared medical appointments/group visits [Internet]. Leawood, Kansas. AAFP. 2018. Available from: https://www.aafp.org/about/ policies/all/shared-medical.html. Accessed June 11, 2018.

4. Careyva B, Salzman B, Plumb E, et al. Patient perceptions of a diabetes group visit experience. J Community Med Health Edu 2012;2:2.

5. Burke RE, O'Grady ET. Group visits hold great potential for improving diabetes care and outcomes, but best practices must be developed. Health Affairs 2012;31:103-9.

doi: 10.3122/jabfm.2018.05.180171

The above letter was referred to the author of the article in question, who offers the following reply.

\section{Re: Wide Gap between Preparation and Scope of Practice of Early Career Family Physicians}

To the Editor: Peterson et al. ${ }^{1}$ have published a stimulating piece that leaves the reader wanting more analysis, which will probably show up in future articles. For all the years since residency education began, a family medicine residency graduate faces a "buyers' market" relative to job opportunities that match one's desired practice. With appropriate guidance from teachers and mentors, residents should be able to clearly write down the values that are important to them, the type of community in which they would hope to practice, and the nature of the patients for whom they would like to care. I have a letter that I wrote in the fall of 1972 with those items and have referred to it as my career has gone along.

This report in the journal raises the issue of the early differentiation of residents in their desired scope of practice. Instead of a "generic stem cell" graduate, we have seen an increase in early choice making, almost immediately after the match has happened. One of the purposes of residency education is to expose residents to patients and communities and practice styles of colleagues that will influence their thinking about future choices. Deciding too early risks closing off learning.

If, however, the problem is, in part, corporate medicine in large cities deciding that fragmented care is what it wants to deliver, those systems should be confronted with the analyses and data that show that family doctors can and will provide comprehensive and integrated care at lower cost and higher quality. In the end, if large systems cannot figure out how to let family doctors "practice at the top of their degree," then graduates can walk away, organize efforts to demand changes in their organization, or find another health system that will. Like unions in the early 20th century that demanded working conditions that met their needs, family doctors can collectively confront organizations that will not let us practice in the ways we are trained. But that discussion needs to happen among family doctors of all ages and generations. Solidarity is power.

My concern is that self-differentiation, economic and family issues, and what is portrayed as a comfortable life may influence choice. Variety is not only the spice of life, it has been shown to positively affect physician happiness. We do not want to see a dissatisfied generation of family doctors stuck in monotonous care systems. If large systems that respect diversity of practice and clinical autonomy and encourage innovation are featured and celebrated by graduates, the industrialized health systems will have to change toward that model of care if they want to recruit new family doctors. Word has a way of getting out.

John J. Frey III, MD University of Wisconsin-Madison, Santa Fe, NM

To see this article online, please go to: http://jabfm.org/content/ 31/5/829. full.

\section{Reference}

1. Peterson LE, Fang B, Puffer JC, Bazemore AW. Wide gap between. preparation and scope of practice of early career family physicians J Am Board Fam Med. 2018;31:181-82.

doi: 10.3122/jabfm.2018.05.180142

The above letter was referred to the author of the article in question, who offers the following reply.

\section{Response: Re: Wide Gap between Preparation and Scope of Practice of Early Career Family Physicians}

To the Editor: I read with interest Dr. Frey's comments spurred by my recent article $^{1}$ on differences between preparation for and provision of different clinical activities seemingly central to the core of family medicine. Like many people, my refrigerator door has many magnets, among my favorites is one the American Academy of Family Physicians sent me that says, "PROUD FAMILY DOC." Lately I have been wondering what it means to be a proud family physician. Our specialty still holds the archetype of the proud family physician as one who is long standing in their community, provides cradle-to-grave care, and will care for their patients when and where they need them. This phenotype is becoming the rare exception to a growing list of "-ists" who care for one part of a patient or only care for them in limited settings.

Should I be proud of my broad-scope training if I do not use it? Should I be proud of the care I provide my patients even if I no longer provide inpatient care, deliver babies, and rarely see children in the office? Should I be proud of my mindset and values? Should I be proud of the history of our specialty when the present may not honor it?

The core of what a family physician is, seems under question. Dr. Frey suggests that family physicians rally together to take down health care systems or create their own. Such collective actions require a sense of community and common purpose that seems to be 